\title{
Entrevista com Danièle Linhart: a instituição da expropriação
}

\author{
Danièle Linhart ${ }^{\mathrm{I}}$, Laurent Aucher ${ }^{\mathrm{II}, 1}$, Frédérique Barnier ${ }^{\mathrm{II}, 2}$ \\ ${ }^{\mathrm{I}}$ Centro Nacional de Pesquisa Científica (Paris, França)

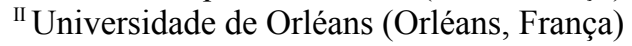

Entrevista concedida a Laurent Aucher e Frédérique Barnier em 22 de maio de 2015 para a revista La vie de idées ${ }^{3}$, traduzida por Eduardo Alessandro Kawamura, Juliana Andrade Oliveira, Luciano Pereira e Selma Borghi Venco. Com a revisão de Marilane Carneiro Di Mario. Socióloga, Danièle Linhart é diretora emérita de pesquisa no Centro Nacional de Pesquisa Científica (Centre national de la recherche scientifique, CNRS), membro do laboratório Grupo de Pesquisa Gênero, Trabalho e Mobilidade do Centro de Pesquisas Sociológicas e Políticas de Paris (GTMCRESPPA) da Unidade Mista de Pesquisa (UMR) do CNRS e das Universidades de Paris 8 e Paris 10. Do taylorismo ao gerenciamento moderno, os modelos de organização do trabalho sempre buscaram, segundo Danièle Linhart, desapropriar os assalariados de seus saberes profissionais. Essa expropriação no trabalho é hoje também subjetiva, o que a torna muito difícil de ser combatida.

\section{Uma abordagem sociológica do trabalho}

Danièle Linhart: Depois de meu vestibular, estudei na classe preparatória na Escola Normal Superior [hypokhâgne] e no Instituto de Ciências Políticas de Paris [Sciences-Po]. Em seguida, me interessei pela sociologia, que estava começando na época, e cheguei em Nanterre nos bons anos de 1967-1968, na mesma turma de trabalhos práticos [TP] de Cohn-Bendit. Havia grandes manifestações da sociedade francesa das quais eu participava, à minha maneira, como simpatizante maoista. Imediatamente me dei conta que, se quiséssemos compreender verdadeiramente a sociedade, teríamos que passar pelo mundo do trabalho. Fui muito influenciada pelos sociólogos que se estudava na época e que diziam, efetivamente, que a sociedade era compreensível pelo filtro do trabalho, uma atividade maior, nobre. Então, eu logo me dirigi à sociologia do trabalho, na qual lecionavam professores como Alain Touraine, Michel Crozier e assistentes como Jean Baudrillard e Pierre Tripier. Todas as pessoas que contribuíam ao debate sobre a evolução e o lugar do trabalho em nossa sociedade. Eu compreendi que era isso que me interessava, isso que eu queria estudar, porque no mundo do trabalho havia um condensado, uma concentração de injustiça social, de desigualdades. Eu havia lido uma grande parte de Marx, na época isso não era nem arcaico nem piegas, e eu achava que a luta de classes tinha um lugar central em nossa sociedade. Comecei a trabalhar no Centro de Pesquisa sobre o Bem-Estar, dirigido por Philippe d'Iribarne, depois eu ingressei no CNRS e fui trabalhar no laboratório dirigido por Jean-Daniel Reynaud, no CNAM ${ }^{4}$. Então, eu comecei a me interessar pelo que se chamava, na época, a "vivência do trabalho", a "vivência", para referir-se

\footnotetext{
1 Doutor em Sociologia, Professor da Universidade de Orléans (Instituto Universitário de Tecnologia, IUT de Bourges), pesquisador filiado ao Centro de Estudos para o Desenvolvimento dos Territórios e do Meio Ambiente e membro associado ao Laboratório de Mudança Política e Social (LCSP) da Universidade Paris Diderot.

2 Doutora em sociologia, Mestre de Conferências na Universidade de Orléans (Instituto Universitário de Tecnologia, IUT de Bourges) e pesquisadora no Centro de Estudos para o Desenvolvimento dos Territórios e do Meio Ambiente (EA 1210).

3 A entrevista original está disponível em: http://www.laviedesidees.fr/L-entreprise-de-depossession-3054.html

4CNAM: Conservatoire National des Arts et Métiers (N.T.).
} 
justamente ao que as pessoas sentem quando elas trabalham. Em meados dos anos 1970 eu me interessei pela questão da subjetividade do trabalho. Na época, havia uma corrente objetivista que examinava a organização do trabalho, as qualificações, as técnicas, mas deixava de lado o que as pessoas sentiam, o que viviam, a natureza das relações que elas tinham umas com as outras. Esse aspecto não era muito analisado, com exceção de certos estudos relacionados ao mundo sindical, às reivindicações e aos conflitos. Como as pessoas fazem para resistirem no trabalho? Essa é uma questão muito tratada agora, mas que eu já achava importante naquela época. Meu primeiro livro, $O$ chamado da sereia, interessava-se, aliás, tanto pela dimensão objetiva, de como o trabalho era organizado, como a exploração funcionava, quanto pela dimensão subjetiva, do que as pessoas sentiam, de qual era a natureza de suas relações com a sociedade, de suas visões de mundo. Esse tem sido meu fio condutor. Depois de 1980, fui relatora da missão "Compreender melhor para melhorar a vida no trabalho", comandada por Chevènement ${ }^{5}$, que, notadamente, originou o Programa Interdisciplinar de Pesquisa sobre Trabalho, Tecnologia, Emprego e Modo de vida [PIRTTEM], no CNRS. Assim, eu tive, verdadeiramente, a possibilidade de compreender as outras disciplinas por meio da criação do Grupo de Interesse Público [GIP] "Mutações Industriais": era uma equipe de pesquisa que queria trabalhar com empresas e sindicatos e a ideia era fazer uma sociologia ligada ao mundo do trabalho, em conjunto com os comitês de empresa, às vezes até mesmo com as diretorias.

\section{Os anos 1980 e a abertura ao mundo das empresas}

Danièle Linhart: No início dos anos 1980, participei durante três anos dos grupos de expressão direta, principalmente, em Corbeil-Essonnes (região de Paris), na Snecma (empresa aeroespacial). Tinha-se a impressão de se estar no centro das notícias, de ver as coisas mudarem, mesmo se, na realidade, elas não mudavam tanto. Nos anos 1985-1986, compreendeu-se que a opressão e a rigidez eram extremamente fortes. Nesse momento, houve uma profunda desilusão, uma desilusão sindical, uma desilusão dos trabalhadores. Eu penso que eles tinham tido uma experiência assustadora, a de constatar que, quando a palavra lhes foi dada, isso em nada se alterou. Essa foi uma experiência terrível.

La vie des idées: Esse é, aliás, o tema central de sua obra Le Torticolis de l'autruche [O torcicolo do avestruz]...

Danièle Linhart: Eu efetivamente escrevi esse livro logo depois de passar três anos na Snecma. Eu tinha compreendido que os coletivos só tinham poder quando eles eram inacessíveis, clandestinos, informais, quando estavam na sombra, na obscuridade. A partir do momento em que eram colocados nas condições de formalização, com um espaço de palavra oficial, sob os olhos ou a vigilância das chefias, as coisas não funcionavam, porque eles deviam ajustar sua posição, discutir sem que houvesse um consenso claro de pontos de vista entre jovens, menos jovens, diplomados e menos diplomados. Percebia-se muito rapidamente que é extremamente complexo o fato de costurar um acordo, encontrar as bases de um consenso para reivindicar, e a partir daí intervir, por exemplo, na organização do trabalho. Isso pode acontecer na prática, pelo "fazer", mas não necessariamente pela ação que requer uma preparação, que pede tempo para preparar as reuniões. A palavra pode ser desviada, retomada, manipulada... "O fazer" existe quando se faz junto, em comum, quando se experiencia junto as coisas e quando elas são realizadas. Eu vi períodos de censura, momentos em que os idosos diziam aos jovens para se calarem porque, por exemplo, eles estavam confiando seus segredos. Finalmente, isso privava os trabalhadores de sua experiência, de seu profissionalismo. Tinha-se voltado à

5 Jean-Pierre Chevènement, ex-ministro e candidato à presidência em 2002 (N.T.). 
situação preconizada por Taylor, com a decomposição das tarefas, quando ele dizia que era preciso procurar na cabeça do trabalhador os conhecimentos para decompor a organização do trabalho, e devolvê-las sob a forma de prescrição. Isso é um pouco do que se tornaram, rapidamente, os grupos de expressão: eles estavam ali para procurarem novos saberes, conhecimentos, de forma a poderem administrá-los, segundo a lógica da racionalidade rentista da empresa. No final dos anos 1980 e início dos anos 1990, chegou-se a um verdadeiro sentimento de impotência. Nesse momento, eu fui admitida no laboratório de Pierre Dubois em Nanterre e comecei a fazer pesquisas sobre a modernização gerencial.

\section{A modernização gerencial}

Danièle Linhart: Com o tempo, eu compreendi que o modelo de modernização gerencial repousava sobre uma estratégia, que realmente tinha sido aplicada no final dos anos 1970: a individualização. Observa-se uma análise muito refinada no livro O novo espírito do capitalismo ${ }^{6}$ de Luc Boltanski e Eve Chiapello. Era difícil de se combater a orientação individualista, tanto pelos sindicatos quanto pelos próprios trabalhadores, que pensavam ser necessário passar por isso para alcançar um mundo do trabalho no qual eles poderiam ser mais responsáveis, melhor considerados, mais reconhecidos... Foi neste momento, igualmente, que eu realmente compreendi a importância dos coletivos naquilo que chamamos de gestão do sofrimento.

La vie des idées: No livro $O$ torcicolo do avestruz você explica que a individualização e o enfraquecimento dos coletivos contribuem para a fragmentação identitária dos trabalhadores...

Danièle Linhart: Eu creio que houve uma tomada de consciência patronal sobre a necessidade de se orquestrar uma metamorfose identitária dos trabalhadores. Esta é realmente uma característica do patronato, do gerencialismo francês, de crer que os trabalhadores são uma desvantagem para a empresa no contexto da mundialização, da concorrência, porque são assalariados particularmente rebeldes. Há uma realidade histórica: a Frente Popular, o peso do $\mathrm{PCF}^{7}$ na França em relação a outros países, o poder da $\mathrm{CGT}^{8}$, as três semanas de greve em maio de 1968... Tudo isso operou um verdadeiro trauma no patronato, que pensava realmente que a classe operária francesa era um grave problema e que o trabalhador não era adaptado, pois era influenciado pela ideologia da luta de classes e por aquilo que Philippe d'Iribarne denomina a "lógica da honra", que faz com que qualquer trabalhador pense que ele sabe como deve trabalhar e que não irá trabalhar de outra forma.

\section{O lugar do trabalho}

Danièle Linhart: Para mim, o lugar do trabalho é ainda totalmente fundamental e a socialização não pode acontecer convenientemente sem o trabalho. É assim que nos tornamos cidadãos, com direitos e deveres, que temos um sentimento de legitimidade e de nosso lugar na sociedade. O lugar do trabalho é certamente mais importante hoje porque houve um desvio do conteúdo e do papel do trabalho. Ele não é mais simplesmente o lugar da legitimação, mas é

\footnotetext{
6 Publicado no Brasil pela Martins Fontes em 2009 (N.T.).

7 Partido Comunista Francês (N.T.).

8 Central Geral dos Trabalhadores (N.T.).
} 
igualmente o lugar da valorização de si, sob um ponto de vista narcísico. É nele que supostamente devemos fazer nossas experiências, nos realizarmos, manifestarmos nossas capacidades, nos desenvolvermos e provarmos que somos bons e melhores que os outros. Há uma narcisização daquilo que está em jogo no trabalho. Antes, era um lugar da socialização, da experiência comunitária, os coletivos assumiam um papel muito importante na regulação do sofrimento. Agora, ele se transformou em um face à face um tanto narcísico entre o trabalho e si mesmo. É nele que devemos nos valorizar, fazermos nossas experiências, nos desenvolvermos... Se não pudermos fazer isso, há uma amputação extremamente importante no plano psíquico, narcísico e, portanto, um sofrimento ainda mais forte. Paradoxalmente, o trabalho ocupa objetivamente menos tempo, 35 horas ao invés das 60 horas do início do século passado, mas ele é muito mais obsessivo. Não há simplesmente uma encenação, mas um real envolvimento de si no trabalho. E há uma grande vulnerabilidade, pois o "eu" não é defendido pelo profissionalismo. Ora, é o profissionalismo que cria justamente uma muralha entre o eu íntimo e o funcionário no trabalho. Hoje há uma confusão entre os dois e isso explica o sofrimento no trabalho que pode conduzir ao suicídio. Na época dos "Trinta Gloriosos", havia o sofrimento e as penosidades, mas elas eram transmitidas pela ideologia da luta de classes, uma crítica moral à organização do trabalho... Agora, as pessoas estão sozinhas e pensam que elas devem provar seu valor. Elas têm tendência a interiorizarem as dificuldades como um fracasso pessoal.

\section{A precariedade subjetiva}

Danièle Linhart: A questão que coloco é saber como a gestão moderna consegue consolidar seu controle sobre os trabalhadores sem recorrer à lógica taylorista que inscreve a coerção e o controle na definição das tarefas. Com o desenvolvimento das atividades terciárias, a questão passa a ser: como o empregador terá domínio suficiente para que os trabalhadores aceitem trabalhar segundo os critérios de rentabilidade almejados no bojo de um capitalismo financeiro a curto prazo? Como obrigar os trabalhadores a se transformarem, por si mesmos, em um pequeno setor de aperfeiçoamento de métodos de trabalho para aplicarem sobre si mesmos os princípios da economia permanente de tempo e de custo e, sobretudo, em situações de trabalho flutuantes? Este é o coração do modelo gerencial moderno: cada trabalhador torna-se um sucedâneo da lógica tayloriana. Não podemos predefinir ex ante o trabalho, cabe ao trabalhador organizar seu próprio trabalho. Marie-Anne Dujarier estudou esse aspecto em seu livro L'Idéal au travail [O ideal no trabalho]. A impossibilidade gerencial de preconizar um tipo de trabalho necessita ser adaptada a cada situação de trabalho, de conceder um pouco de autonomia aos trabalhadores.

La vie des idées: Em seu último livro La comédie humaine du travail [A comédia humana do trabalho], você explica que, com a precarização subjetiva, há um duplo processo. Desestabilizam-se as pessoas deixando-as "sob o fio da navalha" - para empregar seus termos a fim de fazê-las sucumbir aos protocolos. Poderia nos explicar esse segundo aspecto?

Danièle Linhart: É necessário efetivamente que essa autonomia seja limitada por métodos padronizados, por metodologias, critérios, processos, procedimentos. Mas como fazer para obrigar pessoas que são relativamente livres a aplicar esses métodos estandardizados? É aí que intervém a precarização subjetiva para, justamente, destituir os trabalhadores de seus saberes, de seus ofícios, de suas experiências, de seus coletivos, de tudo o que lhes tranquiliza e

9 Termo empregado para identificar o período entre 1945 e 1975, quando, após a Segunda Guerra Mundial, vivenciou-se crescimento e prosperidade (N.T.). 
que traz serenidade no trabalho. Privando-os via mudanças permanentes, pois a partir do momento em que tudo muda constantemente, os trabalhadores perdem suas referências e são precarizados subjetivamente. Mesmo se forem funcionários estáveis, eles são obrigados a buscar os "bons" procedimentos, as "boas" práticas. Eles são obrigados, pois eles não dominam mais nada. A precarização subjetiva consiste justamente em instalar um sentimento de vulnerabilidade idêntico aos trabalhadores precários mesmo entre aqueles que não o sejam. Eles são desestabilizados para que se apeguem aos códigos. Realizei um número considerável de entrevistas em diversos setores e eu ouço as pessoas dizendo que não suportam mais. Elas explicam como há infindáveis reestruturações de serviços, reorganização de funções, modificações de missões... Por exemplo, no "Pôle emploi"10, os trabalhadores explicam que tudo muda o tempo todo. Alguns dizem: "se você pedir para eu me situar no organograma, eu não poderei fazê-lo. Eu não sei mais para quem eu respondo". Há, então, um sentimento de falta de controle que está ocasionando um estado de ansiedade permanente. Outro exemplo, o das enfermeiras que dizem: "Eles nos trocam constantemente de serviço. Não conhecemos os armários ou onde ficam os medicamentos. Antes, sabíamos que certo medicamento estava aqui, tal instrumento lá... Agora, como nos trocam permanentemente, não sabemos mais. Perdemos tempo. Queremos ganhar tempo, mas corremos o risco de cometer erros". Tudo isso gera apreensão, que vai do medo à ansiedade. E, então, enquanto se diz: "É muito simples. É preciso fazer assim", os trabalhadores se apegam às práticas, aos procedimentos, aos métodos desenvolvidos por especialistas que não conhecem a profissão, e que são absolutamente imprecisos, qualquer que seja o setor. Mas as pessoas os aceitam porque têm um profundo sentimento de precariedade, de impotência, de ausência de controle sobre seu trabalho. Assim, há uma perda de sentido porque não é mais o sentido do seu trabalho, segundo as regras do ofício, segundo sua experiência, segundo aquilo que conduziu-os a serem os profissionais que são, mas é uma espécie de lógica gerencial que os conduz. Recentemente, um responsável pelo departamento de recursos humanos me disse: "O meu papel é produzir amnésia". Esta fórmula é extraordinária, ela mostra que, com as mudanças permanentes, as pessoas devem esquecer como elas trabalham antes de aplicarem esses métodos.

\section{A ideologia gerencialista}

Danièle Linhart: Essa ideologia repousa primeiramente sobre a guerra econômica e a necessidade de consenso para enfrentá-la. Essa ideia de consenso sempre foi uma obsessão de Taylor e de Ford. Como estamos falando de regimes democráticos, as regras do jogo do mundo do trabalho não podem ser fundamentadas na imposição ou em formas antidemocráticas. É necessário obter a adesão das pessoas. A opinião pública foi completamente doutrinada pelos discursos em torno da defesa do emprego, da defesa da posição da França no mundo e até mesmo pelo discurso humanista da realização de si mesmo. Tudo isso procede da mesma retórica, a da empresa que tem necessidade de se desobrigar. Não são os assalariados que precisam ser liberados para que eles possam se exprimir no seu trabalho, influenciar seu trabalho, é a empresa que deve se desobrigar, que deve se simplificar. Esta é a função ideológica. Esse discurso é acompanhado de uma reabilitação da gestão apresentada, simultaneamente, como o carro-chefe da guerra econômica e como um modelo de indulgência. A isso se soma um discurso de culpabilização dos assalariados: "A França é um país onde os trabalhadores têm leis trabalhistas muito protetoras, onde eles custam muito caro às empresas. Com as 35 horas, eles trabalham muito pouco...”. Em A comédia humana do trabalho eu conto como, em um colóquio de gestores da saúde, o diretor de um grande CHU (Centro Hospitalar Universitário) inicia sua fala introdutória sobre os riscos psicossociais ${ }^{11}$ e, em seguida, ele para e diz: "Se há alguém aqui

10 Pôle Emploi é uma entidade equivalente ao SINE no Brasil (N.T.).

11 Jargão utilizado para referir-se aos riscos que são consequência das modificações na organização do trabalho (N.T.) 
nesta sala que pensa que é vítima de riscos psicossociais, que venha comigo, eu o levo à China...”. E ninguém na sala reagiu.

\section{Trabalho prescrito, trabalho real}

Danièle Linhart: Há uma grande diferença entre o trabalho prescrito, o que as pessoas supostamente devem fazer de acordo com os organogramas, com as prescrições do trabalho, com as descrições de cargos e de atividades e o que eles realmente fazem. Isso acontece simplesmente porque os procedimentos foram concebidos por engenheiros em seus escritórios. Assim, há uma dimensão que é abstrata por definição, uma vez que não é no local de trabalho que eles são concebidos, e igualmente uma relativa inoperabilidade desses procedimentos em relação aos imprevistos do trabalho concreto. Quando se trabalha, nunca é como imaginamos. Nós não podemos prever todas as contingências, as disfuncionalidades, as imperfeições, as surpresas que constituem a realidade do trabalho cotidiano. Para conseguir alcançar os objetivos fixados, os trabalhadores são obrigados a interpretar minimamente essas prescrições para dar-lhes vida, para dar-lhes sentido, mas também para serem capazes de superar todas as anomalias pelas quais são confrontados diante da realidade de seu trabalho cotidiano. Inventar essas pequenas astúcias, testar "de ouvido", ouvindo ou "farejando", sentir, por exemplo, se uma máquina irá aquecer e, assim, desacelerar, logo, desenvolver toda uma série de conhecimentos e competências específicas próprias a um grupo social, a um grupo profissional. É também o espaço de uma racionalidade que é compartilhado coletivamente. Por exemplo, em um coletivo, os mais velhos ensinam os mais jovens: "Atenção, você vai machucar suas costas se você fizer isso dessa ou daquela forma". Muitos acidentes de trabalho foram evitados graças aos coletivos nos quais se compartilha, se oferecem conhecimentos, saberes que permutamos, que testamos. Há o sentimento de um destino comum, de valores comuns: o que é justo e injusto, moral e imoral. O trabalho real é, em relação ao trabalho prescrito, uma transgressão e toda uma vida coletiva é criada em torno dessa clandestinidade, dessa transgressão. Essa vida social, essa sociabilidade se impregna também de um sentido político. Há, em torno do trabalho real, tomadas de consciência coletivas, sindicais, políticas, morais, que fazem as pessoas sentirem que elas compreendem o que lhes está acontecendo e porquê. Elas podem vincular suas experiências às dimensões econômicas e políticas que vão além de seu local de trabalho. E lá, a ideologia da luta de classes, da exploração capitalista, faz sentido. Elas podem sair do confinamento do microcosmo de seu local de trabalho, tentando decifrar o que está acontecendo e, portanto, posicionar-se como ator coletivo. Hoje em dia, com a individualização e a atomização, as pessoas já não têm esse benefício: elas enfrentam tudo isso de forma solitária.

La vie des idées: Isso é o que você mostra em A comédia humana do trabalho, entre o modelo taylorista, que valorizava a desumanização, mas que permitia justamente a expressão desses elementos...

Danièle Linhart: Que o permitia objetivamente, não intencionalmente. Mas que deixava espaço, que não podia se opor a isso.

La vie des idées: $\mathrm{E}$ a passagem ao modelo gerencial contemporâneo, que valoriza a super-humanização e que, ao contrário, é um ataque sistemático a essa possibilidade de se organizar coletivamente.

Danièle Linhart: E de pensar coletivamente, sobretudo de pensar coletivamente. 


\section{A racionalização unidimensional}

Danièle Linhart: Toda a lógica taylorista, fordista e moderna está baseada na one best way [a melhor maneira]. A ideia de Taylor consiste em dizer que não existem soluções locais. Sua obsessão sempre foi a de encontrar a única e melhor maneira de organizar o trabalho das pessoas. Ora, em função das circunstâncias, dos tipos de trabalho, das experiências, as pessoas deveriam ser capazes de desenvolver suas próprias formas de trabalhar, adaptadas às suas ferramentas, ao seu público, às suas possibilidades. O que é obviamente impensável porque escapa a todo controle. Quando eu ouço, por exemplo, os condutores de trem me dizer: "Na linha $\mathrm{C}$, a gente é obrigado a dirigir com o pé no freio, mas não o dizemos porque poderíamos ser demitidos. Sabemos que as regras não são viáveis e que, se precisássemos frear [para realizar um trabalho correto], levaria muito mais tempo. Então, a gente chega o tempo todo atrasado e a gente é repreendido o tempo todo". Os condutores sabem muito bem o que deveria ser mudado, melhorado, o que deveria ser feito. Mas seus pontos de vista não são levados em conta. As pessoas estão vivendo sempre naquilo que Yves Clot, com razão, chama de "o trabalho impedido": eles não podem fazer o que é preciso para serem eficazes porque eles não têm a oportunidade de influenciar na definição do conteúdo do seu trabalho e do seu ambiente. É o resultado dessa lógica da "melhor maneira".

La vie des idées: Uma única racionalidade...

Danièle Linhart: Há uma única racionalidade preconizada por Taylor e que agora é difundida pelos grandes consultores, que a recomendam, dos aeroportos aos hospitais psiquiátricos, para dizer às pessoas como trabalhar. A realidade contemporânea é a de indivíduos confrontados com essa enorme máquina da exploração capitalista financeirizada num mundo em mudança, em um mundo do trabalho no qual a prática da mudança é sistemática. As pessoas são realmente como pequenas pétalas sobre o mar, submetidas às marés, incapazes de mudar algo, não podem influenciar em nada. Esse é o drama atual no mundo do trabalho: nele as pessoas são confrontadas sozinhas e estão cada vez mais implicadas em suas personalidades, naquilo que lhes especifica, na sua identidade...

\section{Endereço para correspondência}

ekawamura@gmail.com

Recebido em: 30/06/2015

Aprovado em: 01/09/2015 